\title{
Research on the Management and Application of Computer Software Engineering
}

\author{
Weina Zhu, Jinzhen Zhan, Haiyan Dang \\ Northwestern Polytechnical University Mingde College, Xi'an Shaanxi, 610124, China
}

Keywords: Computer software engineering, Management, Application measures.

\begin{abstract}
In the process of computer software engineering management, according to the application requirements and features of network information technology, the relevant departments shall work out management solutions to manage and control each kind of models rationally, ensure the application effect of software engineering, improve the safety and reliability, and meet the needs of the actual development, laying a foundation for the subsequent progress.
\end{abstract}

\section{Introduction}

In the actual process of the development of computer software engineering, the related management department shall establish a variety of control systems, and maintain all aspects of work contents and requirements. To a certain extent, the related departments should highlight the engineering management advantages, and ensure the application effect, as well as the innovation of management and control system.

\section{The management measures of computer software engineering}

During the management of computer software engineering, the relevant departments should formulate the perfect management solutions, and make clear of working characteristics and requirements. Moreover, the diversified control systems should be established, and, the relationship among all kinds of systems should be maintained, so as to achieve the desired purpose. The specific measures are as follows.

\subsection{Strict controls over risks}

In the process of applying software engineering system, there are always some risk problems, mainly because there are many potential risks. And the reasonable management must be taken, and the security and reliability of the system must be guaranteed, so as to meet the demand of practical management work. First of all, during the management of risk, we should establish a modern risk management system plan to establish the correct concept and to guarantee the working effect. In the meantime, the perfect risk management system shall be formulated, and the job requirements should be specified. And the hidden danger of risks existing in the development and use of software projects must be better recognized. In order to protect it well, the risks must be evaded through a reasonable way. Second, strengthen risk management and control. Combined with the practical work requirement, implement relevant control work, and reduce the software engineering using economic losses, and ensure the internal security and reliability of project. Finally, the development and management of software engineering control should be management and control in a proper way. According to the actual application requirements, record the risk problem in details. On the condition of the application of advanced supervision and management methods, improve the reliability and validity of software engineering on use, to make it in the running state of zero risk. For example, during the construction management system, the risk identification during the whole process must be aware, and from software development to actual use, the deep analysis must be required, so that the risks can be found in time. Under the situation of expanding software space, the reading ability of it 
must be enhanced, so as to use the software technology properly and ensure the working effects. During this period, you can also set a risk tracking monitoring system. During the period of tracking management, if there is any risk found in the software structure, the job, such as the remote processing, must be done. With the supports of risk feedback technology and combined the technology of online user management, the risks can be reflected in real time, which will be better to dealt with.

\subsection{The construction of related engineering management system}

In the process of software project management, the relevant departments shall explicate the establishment characteristics of the quality system, and develop the high-level management work properly. Meanwhile, the diversified amount control system should be established. Taking the software engineering as the main management basis, the relevant departments shall establish a modern scientific management system, and strengthen project management, as well as maintain its effectiveness. During this period, the security technology and advanced professional knowledge must be used in a reasonable way. The reliability and validity of management must be enhanced. In the case of increasing the technology content, the advantage of professional information technology must be taken. At the same time, with the support of management system, it is necessary to clarify management requirements of the theory part and practice part of software engineering. The advanced experience at home and abroad must be referred to actively. Use computer technology rationally, and enrich the content of the software engineering, which benefits to the improvement of project management working effect and the development of software engineering, so as to improve the economic benefit. For example, in the related management work, the theory and practice of combining management system can be built. In this case, with the theory of professional knowledge, to combine the management elements better, the richness and the rationality of the guarantee system construction can be ensured. During this period, the relevant administrative departments should use the information technology method scientifically, and construct the modern engineering support management system, to ensure the relevant working effects. In order to better manage the software engineering, the relevant departments shall build a modernized practice system, and connect it with the software engineering management, which can guarantee the management effect, and create a good environment for development.

\subsection{The construction of a team of high-quality talents}

During the management of software engineering, a high-quality talent team should be built, and the skilled talents with high professional quality and rich work experience should be employed to ensure the management effect. First of all, when hire the talents for software development, their grasps of advanced professional knowledge and skills must be assessed, and their working level must be meet the national requirements. By the way, the diversified management mechanism must be built. Next, the staff must be trained periodically, especially for their professional knowledge and technical abilities. With mutual exchange among staffs, the correct concept must be in mind. And the risks of the software projects must be prevent. They must ensure that the technology development must meet the requirements of the current ages. The reliability and validity of management must be improved as well. Finally, the ideological and political knowledge training must be taken by staff, so that their qualities of professional ethics can be enhanced. What's more, the advanced management mechanism should be established. On the condition of ensure the working effect, the demand of current software engineering management must be met, so that their long-term development and progress can be maintained.

\subsection{Formulate a sound responsibility system}

During the management of software engineering, the relevant departments should formulate a perfect responsibility system, and standardize staff behavior and enhance their enthusiasm. First of all, it is necessary to divide software engineering management into several areas of responsibility, and clarify the responsibilities of all aspects, so as to establish the correct view of responsibility for the 
staff and enhance their enthusiasm. Secondly, the dynamical monitor and management of the responsibility area must be required. Find out the existing problems in time, and take effective measures to deal with the problems, then ensure the working effect. Finally, responsibility system shall be linked with rewards and punishment system, and take the periodic inspection on the actual situation in responsibility area. Once found that there were problems, the reasonable ways to solve the problem must be taken, and the strict punishment against regional head must be implemented. As the same, the level of project management work in the area of the responsibility is higher, the head should be granted enough reward, so as to improve the effect of management work.

\subsection{The comprehensive management to the organizational structure}

In the process of software project management, the relevant departments shall conduct reasonable management to organization, and make clear of the completion of tasks of software development. With the mutual exchange and communication, the relevant work must be proceeded orderly, and the establishment perfect development system must be guaranteed. At the same time, during the development of large-scale software products, it is necessary to promote the coordination and cooperation of staff at each stage, to establish a diversified management mechanism and to create a sound development system.

\subsection{The comprehensive management to customers}

During the management of computer software engineering, the management to customers must be paid attention to. Combines the characteristics of customer service and requirements, find out the existing problems in software engineering in time and take effective measures to deal with problems. After having an idea of what the customers require, the coordination and control of software project must be guided, so as to make full use of advanced technology. At the same time, with the form of information data feedback, the actual needs of users must be indicated, and the feasibility of technology research and development work can be guaranteed. Also, the level of software engineering technology will be improved, then the desired aims for management can be attained.

\section{The measures of the application on computer software engineering}

With the development of the country, the level of national economy goes up. Meanwhile, people's requirement for computers are improved also. People want better computer software, which requires the knowledge of different areas and subjects. The role of software engineering will be fully played and the application effectiveness of the related technology will be enhanced, so that the management work can be enhanced. The specific measures are as follows.

\subsection{The measures on the application in the office}

In daily work, software engineering has already spread. At present, most people in office are using software engineering to carry out related activities, such as the network office application software and data software, etc. According to the business development requirement of the enterprises, and combined the data process characteristics, the modern office mechanism will be established, and the working procedures and methods will be simplified. Enhance the management effectiveness of data information, coordinate the relations between office systems and big data, then improve the data utilization. At the same time, when in office, the relevant staff can make use of the software engineering, and collect data and process information. Within the relevant interface, the staff can increase data storage, and improve the data query mechanism, so as to guarantee the working reliability. For example, in the process of application technology of data, search for the big data, and have a comprehensive understanding of the actual situation of consumer market, then set up a special management and control mechanism. Also, reform office procedures and operation form, so that the modern control environment can be formed. 


\subsection{The measures of the application in the financial field}

In recent years, the software engineering has been used in China's financial enterprises operation and management, which achieved good results. It enhances its own economic efficiency. By the way, it not only improves the service convenience, but also establish good market image, and enhance its credibility. For example, during the use of software engineering, the bank can provide terminal services to users by means of human-computer communication interface, so that users can save queuing time during consulting and handling business. At the same time, the application of software engineering, can ensure rigorous and encryption when the information data conveys, which can make users deal with each other in the safe environment, so that the serious economic losses can be avoided. In addition, the application software engineering technology of financial enterprise is beneficial to simplify the engineering process, to improve the work effect of financial management and to meet the real needs of users. Therefore, in the process of future development, financial enterprises need to rationally use advanced software engineering technology, and create diversified management mechanism and build the favorable development environment.

\subsection{The measures of the application in colleges and universities}

In the traditional university management, only manual operation method can be used. Every time students' information statistics is carried out, which could waste a lot of time and money, and the working results cannot be guaranteed. In recent years, some universities begin to use software engineering to the management work. They collect and organize information of students through this, which gradually improve the data management level, and increase the intensity of the use of software engineering in colleges and universities. Students' information can be recorded and coped with when put the related technologies into use. Students can check their own grades and information through the online system, which enhance the education management. Schools can enhance their teaching qualities and levels, and shorten the gaps between the teacher and students. On the basis of expanding the learning channels of students, the way of using software engineering needs to be innovated. With the diversified data information support, the management level of colleges and universities is greatly improved. In addition, the application of software engineering is conducive to creating micro-classes for students, so that students can learn professional knowledge by network information technology, and the teaching work effect can be improved.

\subsection{The measures of the application in engineering project management}

The traditional management way already cannot meet the actual development needs during engineering project management. The application of software engineering facilitate to update the data information for the project management enterprises. With the perfect strategic plan, combined the information technology and competitive advantage, the sustainable development can be prompted. Enterprises need to collect and arrange the information data of the project when apply the software engineering. After the reasonable identification, improve the information storage and the effect of work transferring, and guarantee the timeliness of processing, as well as improve retrieval convenience. At the same time, in the process of using information technology, the advantage of projects should be clear. When penetrated the science and technology, its economic benefit and social benefit should be improved, and the management efficiency must be guaranteed.

For example, in the process of designing engineering project, designers can links the 2d with 3d graphics technology through the software engineering. Based on improving its design level, a diversified drawing technology mechanism can be created, which can meet the demand of engineering management.

\subsection{The measures of the applications in communications equipment}

Now people's living levels gradually improve, and the communication equipment has become the necessary items. Most of the communications equipment company has fused software engineering technology into them, and developed the advanced APP, which can not only enrich people's daily life, 
but also can improve the communication efficiency, promote the communication between people, and play the positive role of related technology. At the same time, during the use of software engineering technology, multimedia technology and communication system can be integrated into each other, so that people can have a good experience through video. When people use mobile phones, the qr code also contains software engineering knowledge and content, which should be paid enough attention and handled in a reasonable way.

\section{Conclusions}

When use the computer software engineering, the relevant departments should make the innovative management plans, aimed to all kinds of contents and requirements, also should build a good development system. At the same time, the management work between the organization and customers must be arranged well, and apply it to the military activities, communications equipment and other activities properly.

\section{References}

[1] Wu Xiaodong. Analysis of Logic Application on Computer Software Engineering, Glamour China, 2016(42):255.

[2] Lin Xuelin. Modern Technology based on Computer Software Engineering, Electronic Test, 2014(17):132-133,146.

[3] Wei huan. Maintenance Measures and Methods of Computer Software Engineering, Decision BBS -- how to establish a theoretical seminar on scientific decision-making mechanism. 2015:166-166.

[4] Chen lei. Management and Maintenance of Computer Software Engineering, Glamour China, 2016(30):299. 